TAO, Vol. 12, No. 4, 695-704, December 2001

NOTES AND CORRESPONDENCE

\title{
The Effect of Spectral Composition on the Photochemical Production of Hydrogen Peroxide in Lake Water
}

\author{
Andrea Y. L. Wong ${ }^{1}$ and George T. F. Wong ${ }^{2, *}$ \\ (Manuscript received 30 January 2001, in final form 27 August 2001)
}

\begin{abstract}
Hydrogen peroxide was produced when samples of lake water were exposed to direct or filtered sunlight in which $U V$ or $U V(B+C)$ light was selectively removed. In all cases, the concentration of hydrogen peroxide increased linearly with time-integrated irradiance. While both visible and UV light can induce the formation of hydrogen peroxide, the contribution from the latter was disproportionately large as it was responsible for about two-thirds of the formation of hydrogen peroxide. Among the UV lights, the contributions from UV-A and UV- $(B+C)$ light were $70 \%$ and $30 \%$ respectively. The contribution from UV-A light was equivalent to about one half of the total production of hydrogen peroxide. Thus, relative to its contribution to the total irradiance in the solar spectrum, UV-A light is the most efficient type of light for the formation of hydrogen peroxide in lake waters.
\end{abstract}

(Key words: Photochemistry, Hydrogen peroxide, Natural water, Lake, UV-A)

\section{INTRODUCTION}

Hydrogen peroxide $\left(\mathrm{H}_{2} \mathrm{O}_{2}\right)$ can act both as an oxidizing and a reducing agent in the aquatic environment (Moffett and Zafiriou 1990). The resulting reactions can alter the speciation of a number of biologically important race elements such as iron (Waite and Morel 1984; Moffett and Zika 1987a; Millero and Sotolongo 1989; King and Farlow 2000), copper (Moffett and Zika 1983, 1987b; Sharma and Millero 1989; Millero et al. 1991), chromium (Pettine and Millero 1990; Pettine et al. 1991) and arsenic (Pettine and Millero 2000). The speciation of these trace elements in turn can affect the biological availability and/or toxicity of these ele-

\footnotetext{
${ }^{1}$ Department of Public Policy, Duke University, Durham, NC 27708

${ }^{2}$ Department of Ocean, Earth and Atmospheric Sciences, Old Dominion University, Norfolk, VA, USA

* Corresponding author address: Prof. George T. F. Wong, Department of Ocean, Earth and Atmospheric Sciences, Old Dominion University, Norfolk, VA 23529-0276, USA

E-mail: gwong@odu.edu
} 
ments so that hydrogen peroxide may play an indirect but significant role in the behaviors of the aquatic ecosystem. Hydrogen peroxide is produced in the aquatic environment primarily by the interactions between dissolved organic matter and sunlight through the following reaction scheme (Cooper et al. 1994; Scully et al. 1996):

$$
\begin{aligned}
& \text { DOM+ light } \rightarrow \mathrm{DOM}^{*}, \\
& \mathrm{DOM}^{*}+\mathrm{O}_{2} \rightarrow \mathrm{O}_{2} \cdot{ }^{-}, \mathrm{HO}_{2}, \\
& \mathrm{HO}_{2}+\mathrm{HO}_{2} \rightarrow \mathrm{H}_{2} \mathrm{O}_{2}+\mathrm{O}_{2}, \\
& \mathrm{HO}_{2}+\mathrm{O}_{2} \cdot+\mathrm{H}_{2} \mathrm{O} \rightarrow \mathrm{H}_{2} \mathrm{O}_{2}+\mathrm{O}_{2}+\mathrm{OH}^{-},
\end{aligned}
$$

and

where DOM is the sunlight-absorbing dissolved organic matter and DOM* is dissolved organic matter in the excited state. On the other hand, the decomposition of hydrogen peroxide in natural waters is caused primarily by biological activities (Petasne and Zika 1997). The abiological auto-decomposition of hydrogen peroxide is relatively slow (Kim 1993; Cooper et al. 1994). One of the major controls on the rate of photochemical formation of hydrogen peroxide in a given sample of water is the intensity and spectral composition of the incident light. Thus, even if all other factors, such as the concentrations and the absorption spectra of the chromophores and the quantum yields for the formation of hydrogen peroxide (Wong 1989), are held constant, the rate of formation of hydrogen peroxide in natural waters as a result of solar irradiation still may vary temporally and spatially since both the intensity of solar irradiation and the solar spectrum are temporally and spatially variable (Kirk 1983). In this study, the relationship between the rate of the formation of hydrogen peroxide and the spectral composition of the incident solar irradiation was investigated.

\section{EXPERIMENTAL}

Two samples of water, Sample A and B, were collected from a man-made lake, Mount Trashmore Lake, in Virginia Beach, Virginia in December, 1995 and October, 1996. The samples were filtered immediately after sample collection through Gelman type A/E glass fiber filters (nominal pore size of $1 \mu \mathrm{m}$ ) to remove the suspended particles and most of the biota and then stored in the dark in a refrigerator at about $5^{\circ} \mathrm{C}$ for at least three days before they were used in the ensuing experiments. During the storage period, most if not all of the hydrogen peroxide present initially in the samples would have decomposed and disappeared (Zika et al. 1985; Johnson et al. 1989; Cooper and Lean 1989). With the probable exception of some bacteria, any residual living organisms in the samples that survived filtration would have died during storage so that any biological decomposition of hydrogen peroxide during the subsequent experiments would be minimized (Udomkit 1994; Kim 1993). The experiments were completed within one month of sample collection. The spectral properties of the stored filtered lake water was determined by measuring its absorbance spectrum relative to distilled de- 
ionized water in $10-\mathrm{cm}$ cells.

In each experiment, the filtered lake water was transferred to an open polyethylene pan and then placed on a platform about $2.5 \mathrm{~m}$ above ground. The filtered lake water was then exposed to full and filtered sunlight either in parallel in two separate pans or in one pan on two consecutive days. The experiments were conducted on cool, sunny days under clear Fall skies with at most occasional broken clouds from the mid-morning (0900) to the mid-afternoon (1500) so that the variations in temperature and solar irradiance and any loss of the sample by evaporation during each experiment were kept to a minimum. The observed changes in temperature and the range of solar irradiance in a given experiment were limited to less than $\pm 3^{\circ} \mathrm{C}$ (Table 1 ) and within a factor of 1.5 to 3 . With the exception of one series of experiments which was conducted at an average temperature of $21^{\circ} \mathrm{C}$, the others were run at 9 and $12^{\circ} \mathrm{C}$. The concentration of hydrogen peroxide in and the temperature of the water and the solar irradiance or time-integrated solar irradiance were monitored with time. The concentration of hydrogen peroxide was determined by the spectrophotometric method of Zhang and Wong (1994). In this method, hydrogen peroxide was allowed to react with added leuco crystal violet in the presence of horseradish peroxidase at $\mathrm{pH} 4$ to form crystal violet. The absorbance of the crystal violet formed was measured at $590 \mathrm{~nm}$ in $10-\mathrm{cm}$ cells. The detection limit and the precision of the method were about $0.02 \mu \mathrm{M}$ and $\pm 1 \%$ (at $0.3 \mu \mathrm{M}$ ), respectively. Solar irradiance was measured by using a Kipp and Zonen SOLRAD solar radiation measurement system which was constituted of a Model CC20 data logger and a Model CM3 pyranometer. The pyranometer acted as a broad band radiometer with a flat spectral sensitiv-

Table 1. Relationship between time-integrated irradiance and time, and, the concentration of hydrogen peroxide and time-integrated irradiance.

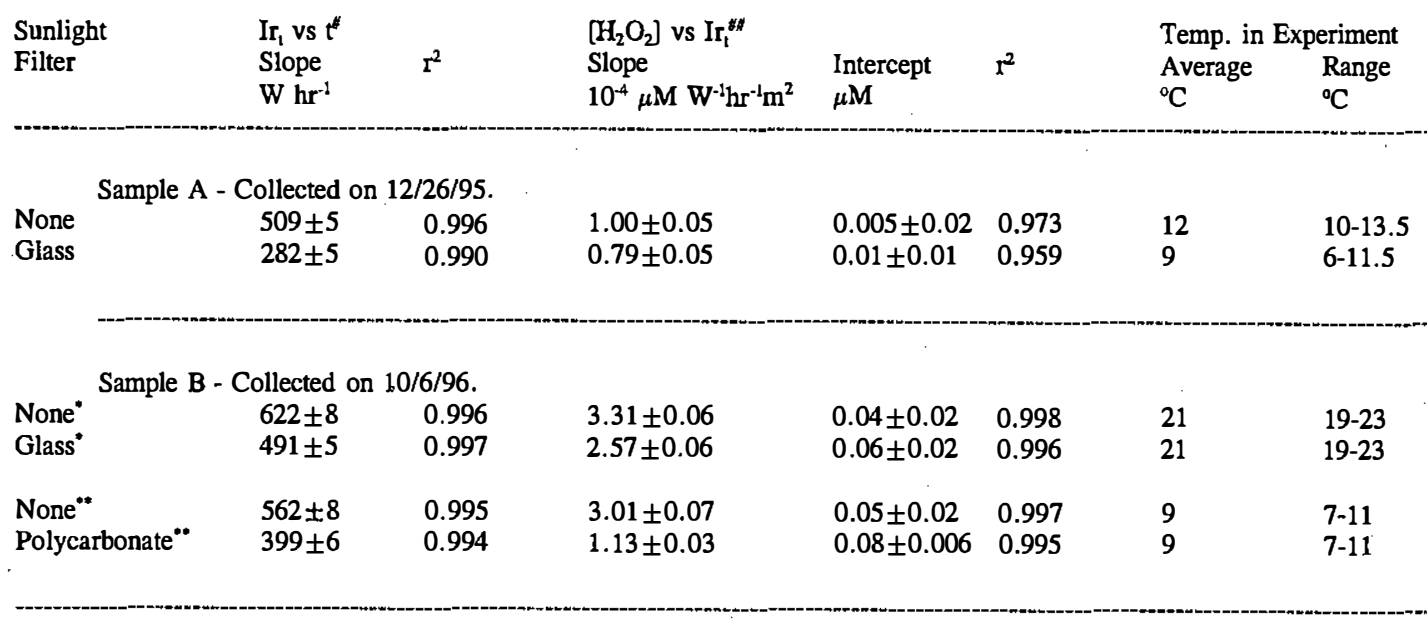

$\mathrm{Ir}_{\mathbf{1}}$ - time-integrated irradiance in $\mathrm{W} \mathrm{hr} \mathrm{m}^{-2}$.

$\mathrm{t}$ - time in hour.

- linear least square analysis through the origin.

* - linear least square analysis.

$r^{2}$ - Correlation coefficient in linear regression analysis.

",** - Experiments run in two simultaneous pairs about one month apart. 
ity between 0.3 and $3 \mu$ and a field of view of $180^{\circ}$. Time-integrated solar irradiance was either read directly from the data logger or estimated by a graphical integration of the relationship between time and irradiance. The spectral composition of the incident sunlight was modified by filtering it through either a piece of $6.0 \mathrm{~mm}$ thick glass plate or a piece of $4.7 \mathrm{~mm}$ thick polycarbonate sheet which was placed above the reaction pan. The spectral properties of these filters were determined by measuring their transmittance spectra relative to air. A control experiment was run by monitoring the concentration of hydrogen peroxide in a sub-sample that was kept in the dark at room temperature at about $20^{\circ} \mathrm{C}$. All the absorbance and transmittance spectra and absorbance at a specified wavelength were measured by using a Beckman Model 5230 double beam scanning spectrophotometer.

\section{RESULTS AND DISCUSSION}

\subsection{Absorption Characteristics of the Sample and Control on the Spectral Composition of the Incident Light}

The solar spectrum can be divided into the ultraviolet (UV, $<400 \mathrm{~nm}$ ), visible (400 to 700 $\mathrm{nm})$ and infrared light $(>700 \mathrm{~nm})$. With their more energetic photons, UV and visible lights are more likely to induce photochemical reactions and they contribute $<10 \%$ and about $50 \%$ of the irradiance in the solar spectrum respectively (Zafiriou 1977; Zika 1981; Kirk 1983). Based on its biological effect, UV light can be further sub-divided into UV-A ( 320 to $400 \mathrm{~nm}$ ), UVB (280 to $320 \mathrm{~nm}$ ) and UV-C (235 to $280 \mathrm{~nm}$ ) lights (Cullen et al. 1992). However, the contributions of these UV lights to the irradiance in the solar spectrum decrease dramatically with decreasing wavelength so that hardly any UV-C light may reach the Earth's surface (Kirk 1983) and induce photochemical reactions in natural waters. The absorbance spectrum of the Mount Trashmore Lake water (Fig. 1) was similar to those found in other natural freshwater (Foster and Morris 1974). At wavelengths longer than $440 \mathrm{~nm}$, the absorbance remained low $(<0.1)$ and rather constant. At shorter wavelengths, the absorbance increased dramatically with decreasing wavelengths, reaching 0.38 at $320 \mathrm{~nm}$ and 0.75 at $280 \mathrm{~nm}$. Thus, the samples did not absorb visible light very effectively. Within the UV range, they absorbed increasingly effectively from UV-A to UV-B to UV-C light.

The transmittance of the glass plate stayed relatively constant between 73 and $83 \%$ at wavelengths above $355 \mathrm{~nm}$ (Fig. 1). Below $355 \mathrm{~nm}$, the transmittance dropped precipitously with decreasing wavelength to $<1 \%$ at $320 \mathrm{~nm}$. Thus, this filter effectively removed all the UV-B and UV-C light and a small fraction of the UV-A light from the incident light. The resulting filtered light that caused photochemical reactions was essentially visible and UV-A light. For the polycarbonate sheet, the transmittance was relatively constant, between 81 and $90 \%$, above $430 \mathrm{~nm}$ (Fig. 1). At lower wavelengths, it dropped to $<1 \%$ below $400 \mathrm{~nm}$. Thus, this filter removed all UV light from the incident light. The resulting filtered light was essentially visible light.

Since the experiments were conducted from the mid-morning to the mid-afternoon, the variation in solar irradiance with time was small. Thus, the time-integrated irradiance was 


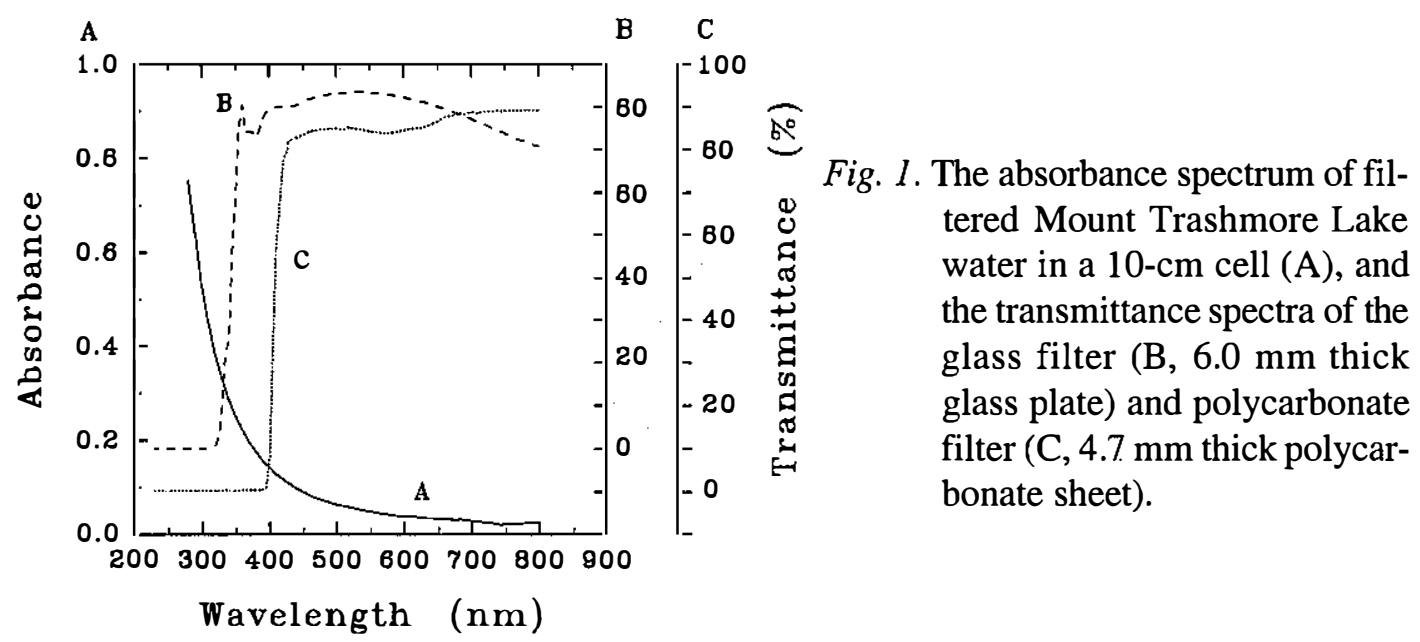

almost linearly related with time in all experiments with correlation coefficients, $\mathrm{r}^{2}$, ranging from 0.990 to 0.997 (Table 1). The slopes of these relationships give the average solar irradiance during these experiments. The average irradiance under direct sunlight, ranging from 509 to $622 \mathrm{~W} \mathrm{~m}^{-2}$, were quite similar in all three experiments (Table 1). For Sample B, experiments under direct sunlight and filtered sunlight were run side-by-side simultaneously. The average irradiance under direct sunlight and sunlight filtered through the glass plate were 622 and $491 \mathrm{~W} \mathrm{~m}^{-2}$ respectively. Since the glass plate filtered out 73 to $83 \%$ of the UV-A and visible lights with wavelengths longer than $355 \mathrm{~nm}$ (Fig. 1), an average correction of $80 \%$ was applied to the irradiance of the filtered light to obtain the irradiance of the UV-A and visible lights of $613 \mathrm{~W} \mathrm{~m}^{-2}$ in the incident solar irradiation. This corresponded to $98 \%$ of the irradiance of the full direct sunlight. Thus, as reported in the literature (Kirk 1983), UV(B+C) light was a minor component of the solar spectrum. The average irradiance under direct sunlight and sunlight filtered through the polycarbonate sheet were 562 and $399 \mathrm{~W} \mathrm{~m}^{-2}$ respectively. The polycarbonate sheet filtered off 81 to $90 \%$ of the visible light with wavelengths longer than $430 \mathrm{~nm}$ (Fig. 1). Using an average value of $85 \%$, the irradiance of visible light was estimated to be $469 \mathrm{~W} \mathrm{~m}^{-2}$ or about $84 \%$ of the irradiance of the full direct sunlight. Thus, UV light constituted only about $16 \%$ of the incident solar irradiation.

\subsection{Photochemical Production of Hydrogen Peroxide in Direct and Filtered Sunlight}

When a sample was kept in the dark, changes in the concentration of hydrogen peroxide with time were within the uncertainties of the analytical method used. Thus, there was negligible non-photochemical production and/or decomposition of hydrogen peroxide. When the samples were exposed to direct or filtered sunlight, as reported previously (Cooper and Zika 1983; Cooper et al. 1988, 1994; Cooper and Lean 1989; Scully et al. 1996), the concentration of hydrogen peroxide in the samples increased steadily with time indicating a photochemical formation of hydrogen peroxide in these waters. While our experimental design measured the net effect between hydrogen peroxide production and decomposition under solar irradiation, the effect from the latter process was probably small since hydrogen peroxide does not un- 
dergo photochemical auto-decomposition readily (Kim 1993; Cooper et al. 1994). The initial concentrations of hydrogen peroxide in the samples ranged between below the detection limit of $0.02 \mu \mathrm{M}$ to $0.09 \mu \mathrm{M}$ while the final concentrations in the experiments, after the exposure of the samples to solar irradiation, ranged between 0.16 and $1.20 \mu \mathrm{M}$. The concentration of hydrogen peroxide increased linearly with the time-integrated irradiance of direct or filtered sunlight with $\mathrm{r}^{2}$ ranging between 0.959 and 0.998. The results from Sample B, which was collected in October, 1996, are shown in Fig. 2 and the results from all the experiments are summarized in Table 1. Sub-samples of Sample B were exposed to direct sunlight on two different days separated by a time period of approximately one month and the rates of production of hydrogen peroxide were $3.31 \times 10^{-4}$ and $3.01 \times 10^{-4} \mu \mathrm{M} \mathrm{W}^{-1} \mathrm{hr}^{-1} \mathrm{~m}^{2}$. The difference between these two rates, which was only about twice of the sum of their statistical uncertainties (Table 1), was minimal. This consistency suggests that the storage of the sample in the dark at $5^{\circ} \mathrm{C}$ over a period of a month did not change the capacity of the sample to produce hydrogen peroxide significantly. Furthermore, these two experiments were conducted at average temperatures of 21 and $9^{\circ} \mathrm{C}$ and these temperatures represented the extremes at which all the experiments were carried out. Thus, apparently, the variations in temperature from one experiment to another also did not affect significantly the capacity of the sample to produce hydrogen peroxide. On the other hand, in the experiments conducted about ten months earlier using Sample A, which was collected from the same lake, the rate of production of hydrogen peroxide was only $1.00 \times 10^{-4} \mu \mathrm{M} \mathrm{W}^{-1} \mathrm{hr}^{-1} \mathrm{~m}^{2}$ or about a third of that found in Sample B. Thus, the capacity to produce hydrogen peroxide could vary significantly with time in a single lake. This temporal variation in the capacity to produce hydrogen peroxide might have been caused by the temporal variations in the concentration or in the chemical nature of the dissolved organic matter in the lake (Cooper and Zika 1983; Cooper et al. 1988, 1994).

The contributions of the various types of light to the formation of hydrogen peroxide are summarized in Table 2. The ratio of the rates of production of hydrogen peroxide under light filtered through the glass plate and under direct sunlight represented the contribution from visible plus UV-A light. The remainder was contributed by UV- $(\mathrm{B}+\mathrm{C})$ light. (It should be

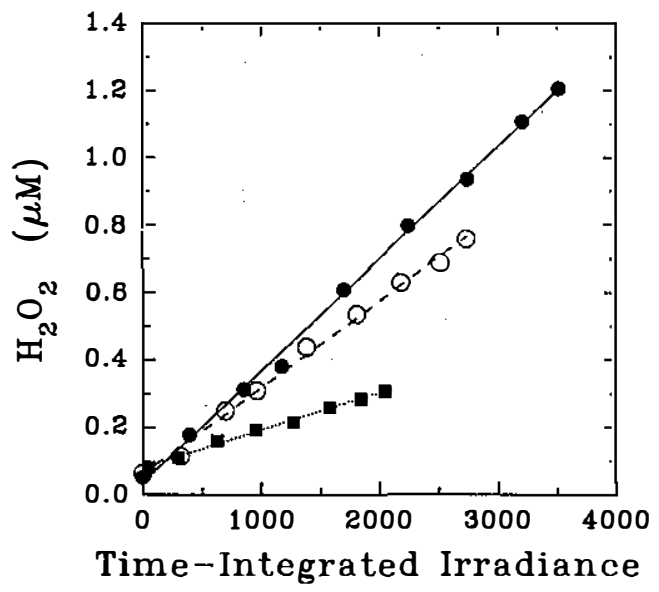

( $\mathrm{W} h \mathrm{r} \mathrm{m}{ }^{-2}$ )
Fig. 2. The relationship between the concentration of hydrogen peroxide $\left(\mathrm{H}_{2} \mathrm{O}_{2}\right)$ and the time-integrated irradiance under direct sunlight $(\boldsymbol{O})$, sunlight filtered through the glass plate $(O)$ and sunlight filtered through the polycarbonate sheet $(\boldsymbol{D})$ in Sample B. The lines represent the best fit through each data set. 
Table 2. Contribution of different spectral ranges in the solar spectrum to the formation of hydrogen peroxide.

\begin{tabular}{|c|c|c|}
\hline & Sample A & Sample B \\
\hline \multicolumn{3}{|c|}{ Rate of production of hydrogen peroxide (in $10^{-4} \mu \mathrm{M} \mathrm{W}^{-1} \mathrm{br}^{-1} \mathrm{~m}^{2}$ ) } \\
\hline Direct sunlight & 1.00 & $3.16^{\circ}$ \\
\hline Visible + UV-A lights ${ }^{*}$ & 0.79 & 2.57 \\
\hline Visible light ${ }^{\# t}$ & n.d. & 1.13 \\
\hline \multicolumn{3}{|c|}{ \% of rate under direct sunlight } \\
\hline Visible + UV-A lights ${ }^{*}$ & 79 & 81 \\
\hline UV- $(B+C)$ light** & 21 & 19 \\
\hline Visible light ${ }^{\prime \prime}$ & n.d. & 36 \\
\hline UV light“ & n.d. & 64 \\
\hline UV-A light* & n.d. & 45 \\
\hline
\end{tabular}

- - Average of two experiments.

* - Calculated by difference.

* - Resulted from light filtered through the glass plate.

* - Resulted from light filtered through the polycarbonate sheet.

n.d. - No data

noted that the contribution of UV-C light to the effect of UV-(B+C) light was probably insignificant since the amount of UV-C light in the solar spectrum at sea level is negligible (Kirk 1983)). Likewise, the ratio of the rates of production of hydrogen peroxide under light filtered through the polycarbonate sheet and under direct sunlight represented the contribution from visible light. The remainder represented the contribution from UV light. Furthermore, the difference between the contributions from UV light and UV- $(B+C)$ light was the contribution from UV-A light. Thus, in Sample B, 64\%, or about two-thirds, of the formation of hydrogen peroxide was caused by UV light while the remaining $36 \%$ was caused by visible light. Since UV light constituted only $16 \%$ of the incident solar irradiance, these results suggest that UV light provided a disproportionately large contribution to the formation of hydrogen peroxide in lake water. Among the UV lights, UV-A and UV- $(B+C)$ light contributed $70 \%$ and $30 \%$ of the formation of hydrogen peroxide by UV light. The contribution of UV-A light was equivalent to $45 \%$, or about one half, of the total production of hydrogen peroxide. Thus, UV-A light was the principle type of light that caused the formation of hydrogen peroxide in lake water. Both Sample A and Sample B were exposed to direct sunlight and sunlight filtered through the glass plate. While the absolute rates of formation of hydrogen peroxide in these two samples varied by a factor of about 3 , virtually identical results were found in terms of the relative 
efficiencies of the different kinds of light in the production of hydrogen peroxide. Thus, visible plus UV-A light contributed 79 and $81 \%$ while UV-(B+C) contributed the remaining 21 and $19 \%$ of the rate of production of hydrogen peroxide in these two samples of water. This consistency might only be fortuitous since only two samples of water from a single lake had been tested. However, had these results been representative, they suggest that the difference in the capacity of Sample A and Sample B to produce hydrogen peroxide was probably caused by a difference in the concentration rather than the chemical nature of the dissolved organic matter in these samples since the relative efficiencies of hydrogen peroxide production in the different ranges of wavelengths would most likely have varied in the latter case. This is probably a reasonable hypothesis since both samples were collected from the same lake system.

At a given light field and a given concentration of a chromophore in a solution, the occurrence of photochemical processes is caused by the combined effect of the absorption characteristics and the quantum yields of the chromophore at different wavelengths, and, the distribution of the photons among the wavelengths of the spectrum of the incident light (Wong 1989). Cooper et al. (1988) reported that the quantum yield in the photochemical formation of hydrogen peroxide in natural waters increased monotonically with increasing absorbance of the water and decreasing wavelengths of the incident light. The increase in quantum yield was especially dramatic in the UV range of wavelengths. Thus, based on quantum yield alone, the absorbance spectrum of the samples of water from Mount Trashmore Lake would suggest that the formation of hydrogen peroxide should have increased with decreasing wavelengths. However, since UV light is a small fraction of solar irradiance, the solar spectrum would favor the formation of hydrogen peroxide at the longer wavelengths in the visible region. Our results indicate that the combined effect of these two major controlling factors in the photochemistry of lake water resulted in UV-A light being the most effective in the formation of hydrogen peroxide. In a recent report, Scully et al. (1996) came to the same conclusion by calculating the weighted quantum yields as a function of wavelengths for the formation of hydrogen peroxide from the measured quantum yields and the estimated photon fluxes in the solar spectrum at the different wavelengths. This study provides direct observational evidence that validates the conclusions of Scully et al. (1996).

\section{CONCLUSIONS}

1. Both visible and UV lights can cause the photochemical formation of hydrogen peroxide in lake water.

2. Between visible and UV lights, the latter makes a bigger contribution to the formation of hydrogen peroxide.

3. Among the UV lights, UV-A light contributes more than UV-B and UV-C lights combined to the formation of hydrogen peroxide. In fact, relative to its contribution to the total irradiance in the solar spectrum, among UV and visible lights, UV-A light is the most efficient type of light for the formation of hydrogen peroxide.

Acknowledgements This work was supported in part by the National Science Foundation 
under grant numbers OCE-9301298 and INT-9515521 to G. T. F. Wong and by the National Science Council of Taiwan when this manuscript was prepared while G. T. F. Wong occupied a research chair at the National Center for Ocean Research (NCOR) of the National Science Council of Taiwan. This was part of a project for the Westinghouse competition completed while A. Y. L. Wong was a student of Kempsville High School (Virginia Beach, VA). This is NCOR Contribution No. 46.

\section{REFERENCES}

Cooper W. J., and D. R. S. Lean, 1989: Hydrogen peroxide concentration in a northern lake: Photochemical formation and diel variability. Environ. Sci. Technol., 23, 1425-1428.

Cooper, W. J., and R. G. Zika, 1983: Photochemical formation of hydrogen peroxide in surface and ground waters exposed to sunlight. Science, 220, 711-712.

Cooper W. J., C. Shao, D. R. S. Lean, A. S. Gordon, and F. E. Scully Jr., 1994: Factors affecting the distribution of $\mathrm{H}_{2} \mathrm{O}_{2}$ in surface waters. In: L. A. Baker (Ed.), Environmental Chemistry of Lakes and Reservoirs. American Chemical Society Advances in Chemistry Series No. 237, American Chemical Society: Washington D.C., 391-422.

Cooper, W. J., R. G. Zika, R. G. Petasne, and J. M. C. Plane, 1988: Photochemical formation of $\mathrm{H}_{2} \mathrm{O}_{2}$ in natural waters exposed to sunlight. Environ. Sci. Technol., 22, 1156-1160.

Cullen J. J., P. J. Neale, and M. P. Lesser, 1992: Biological weighting function for the inhibition of phytoplankton photosynthesis by ulraviolet radiation. Science, 258, 646-650.

Foster P., and A. W. Morris, 1974: Ultra-violet absorption characteristics of natural waters. Water Res., 8, 137-142.

Johnson K. S., S. W. Willason, D. A. Wiesenburg, S. E. Lohrenz, and R. A. Arnone, 1989: Hydrogen peroxide in the western Mediterranean Sea: a tracer for vertical advection. Deep-Sea Res., 36, 241-254.

Kim D.-B., 1993: Production and decomposition of hydrogen peroxide by marine phytoplankton. Ph.D. thesis, Old Dominion University, Norfolk, Virginia. 178 pp.

King, D. W., and R. Farlow, 2000: Role of carbonate speciation on the oxidation of Fe(II) by $\mathrm{H}_{2} \mathrm{O}_{2}$. Mar. Chem., 70, 201-209.

Kirk J. T. O., 1983: Light and photosynthesis in aquatic ecosystems, Cambridge University Press: Cambridge.

Millero F. J., and S. Sotolongo, 1989: The oxidation of Fe(II) with hydrogen peroxide in seawater. Geochim. Cosmochim. Acta, 53, 1867-1873.

Millero F. J., V. K. Sharma, and B. Karn, 1991: The rate of reduction of copper (II) with hydrogen peroxide in seawater. Mar. Chem., 36, 71-83.

Moffett J. W., and O. C. Zafiriou, 1990: An investigation of hydrogen peroxide chemistry in surface waters of Vineyard Sound with $\mathrm{H}_{2}{ }^{18} \mathrm{O}_{2}$ and ${ }^{18} \mathrm{O}_{2}$. Limnol. Oceanogr., 35, 12211229.

Moffett J. W., and R. G. Zika, 1983: Oxidation kinetics of copper(I) in seawater: Implications for its existence in the marine environment. Mar. Chem., 13, 235-251.

Moffett J. W., and R. G. Zika, 1987a: Reaction kinetics of hydrogen peroxide with copper and 
iron in seawater. Environ. Sci. Technol., 21, 804-809.

Moffett J. W., and R. G. Zika, 1987b: Photochemistry of copper complexes in sea water. In: R. G. Zika and W. J. Cooper (Eds.), Photochemistry of Environmental Aquatic Systems, American Chemical Society Symposium Series No. 327, American Chemical Society: Washington D.C, 111-129.

Petasne, R. G., and R. G. Zika, 1997: Hydrogen peroxide lifetimes in south Florida coastal and offshore waters. Mar. Chem., 56, 215-225.

Pettine M., and F. J. Millero, 1990: Chromium speciation in seawater: The probable role of hydrogen peroxide. Limnol. Oceanogr., 35, 730-736.

Pettine M., and F. J. Millero, 2000: Effect of metals on the oxidation of As(III) with $\mathrm{H}_{2} \mathrm{O}_{2}$. Mar. Chem., 70, 223-234.

Pettine M., F. J. Millero, and T. La Noce, 1991: Chromium(III) interactions in seawater through its oxidation kinetics. Mar. Chem., 34, 29-46.

Scully N. M., D. J. McQueen, D. R. S. Lean, and W. J. Cooper, 1996: Hydrogen peroxide formation: The interaction of ultraviolet radiation and dissolved organic carbon in lake waters along a 43-75oN gradient. Limnol. Oceanogr., 41, 540-548.

Sharma V. K., and F. J. Millero, 1989: The oxidation of $\mathrm{Cu}(\mathrm{I})$ with hydrogen peroxide in natural waters. Geochim. Cosmochim. Acta, 53, 2269-2276.

Udomkit, A., 1994: lodate transformation by marine phytoplankton. $\mathrm{Ph}$. D. thesis, Old Dominion University, Norfolk, Virginia, 124 pp.

Waite T. D., and F. M. M. Morel, 1984: Photoreductive dissolution of colloidal iron oxides in natural waters. Environ. Sci. Technol., 18, 860-868.

Wong, G. T. F., 1989: Photochemical Reactions. In: S. E. J $\phi$ rgensen and M. J. Gromiec (Eds.), Mathematical Submodels in Water Quality Systems, Elsevier: Amsterdam, 195216.

Zafiriou, O. C., 1977: Marine organic photochemistry previewed. Mar. Chem., 5, 497-522.

Zhang L. -S., and G. T. F. Wong, 1994: Spectrophotometric determination of $\mathrm{H}_{2} \mathrm{O}_{2}$ in marine waters with leuco crystal violet. Talanta, 41, 2137-2145.

Zika, R. G., 1981: Marine organic photochemistry. In: E. K. Duursma and R. Dawson (Eds.), Marine Organic Chemistry, Elsevier, Amsterdam, 299-325.

Zika R. G., E. S. Salzman, and W. J. Cooper, 1985: Hydrogen peroxide concentrations in the Peru upwelling area. Mar. Chem., 17, 265-275. 